\title{
What are the optimum components in a care bundle aimed at reducing post- operative pulmonary complications in high-risk patients?
}

Sophie V. Griffiths ${ }^{1}$, Daniel H. Conway², POPC-CB Investigators, Michael Sander ${ }^{3}$, Ib Jammer ${ }^{4,5}$, Michael P. W. Grocott ${ }^{6}$ and Ben C. Creagh-Brown ${ }^{7,8^{*}}$

\begin{abstract}
Background: Post-operative pulmonary complications (POPC) are common, predictable and associated with increased morbidity and mortality, independent of pre-operative risk. Interventions to reduce the incidence of POPC have been studied individually, but the use of a care bundle has not been widely investigated. The purpose of our work was to use Delphi consensus methodology and an independently chosen expert panel to formulate a care bundle for patients identified as being at high of POPC, as preparation towards an evaluation of its effectiveness at reducing POPC.
\end{abstract}

Methods: We performed a survey of members of the ESICM POIC section to inform a Delphi consensus and to share their opinions on a care bundle to reduce POPC, the POPC-CB. We formed a team of 36 experts to participate in and complete an email-based Delphi consensus over three rounds, leading to the formulation of the POPC-CB.

Results: The survey had 362 respondents and informed the design of the Delphi consensus. The Delphi consensus resulted in a proposed POPC-CB that incorporates components before surgery-supervised exercise programmes and inspiratory muscle training, during surgery, low tidal volume ventilation with individualised PEEP (positive end-expiratory pressure), use of routine monitoring to avoid hyperoxia and efforts made to limit neuromuscular blockade, and post-operatively, deep breathing exercises and elevation of the head of the bed.

Conclusion: A care bundle has been suggested for evaluation in surgical patients at high risk of POPC. Evaluation of feasibility of both implementation and effectiveness is now indicated.

Keywords: Post-operative pulmonary complications, Nosocomial pneumonia, Intra-operative ventilation, Inspiratory muscle training, Care bundle, Delphi consensus

\footnotetext{
*Correspondence: bencb@nhs.net

${ }^{7}$ Intensive Care Unit, Royal Surrey County Hospital, Guildford GU2 7XX, UK

${ }^{8}$ Surrey Perioperative Anaesthetic Critical care collaborative group (SPACeR),

FHMS, University of Surrey, Guildford GU2 7XH, UK

Full list of author information is available at the end of the article
} 


\section{Background}

Post-operative pulmonary complications (POPC) are defined as 'a pulmonary abnormality that produces identifiable disease or dysfunction that is clinically significant and adversely affects the clinical course' (Restrepo and Braverman 2015). They are common, with a reported incidence ranging from $2-40 \%$, and adverse outcomes include mortality, with studies reporting that 1 in 5 patients with POPC will die within 30 days of surgery, and the average hospital stay is lengthened by 8 days (Restrepo and Braverman 2015). A recent international prospective study (LAS VEGAS) of 9864 patients suggested that $28 \%$ of patients are at "high risk" of developing POPC and in this cohort, the incidence of POPC is of $19.2 \%$, with respiratory failure affecting $3.4 \%$ (Rogerson et al. 2017). Unplanned supplemental use of oxygen is the commonest POPC, and in another contemporary study, even this 'mild' POPC was associated with increased risk of mortality and morbidity (Fernandez-Bustamante et al. 2017).

Alongside other perioperative complications, POPC affect long-term outcomes, with patients having lower long-term survival rates following POPC independent of preoperative risk (Khuri et al. 2005). Furthermore, the economic burden of POPC is substantial, with a $55 \%$ increase in hospital costs in non-cardiac patients (Shander et al. 2011). Reduction in the rate of POPC starts with the recognition of moderate- and high-risk patients through the use of validated tools such as ARISCAT (Assess Respiratory rIsk in Surgical patients in CATalonia) (Canet et al. 2010; Canet et al. 2015).

Enhanced recovery (ER) pathways are advocated as 'standard of care' for major surgery, and there are pathways specific to each surgical specialty (Ljungqvist et al. 2017). Several aspects of the pathways are either established to be associated with reduced POPC (minimally invasive surgery (Lee et al. 2015)) or strongly suspected of being associated with reduced POPC (early mobilisation (Pasquina and Walder 2003)). Adherence to ER components is highly variable, and improved adherence has been associated with improved outcomes (Pecorelli et al. 2017).

Several perioperative interventions aiming to reduce the incidence of POPC have been studied sometimes in combination. A care bundle (CB) is a group of interventions that when used together have greater clinical effect than when used individually. A CB for POPC used in the 'I COUGH' study demonstrated a trend towards reduction in $\mathrm{POPC}$, and $\mathrm{CBs}$ have significantly improved outcomes in the critical care environment to prevent ventilator-associated pneumonia (Rello et al. 2013).
The Delphi consensus method was first introduced by the RAND corporation in Santa Monica in the 1950s. The method involves gathering expert opinions through rounds of questions and bringing these opinions together to establish a consensus. Each round is followed by anonymous feedback to all participants, and the results of the previous round are then used to create the subsequent round. This means that over the rounds, a consensus can be derived which is as reliable as possible (Dalkey and Helmer 1963).

Our primary objective was to recruit a team of experts to participate in an electronic Delphi consensus, leading to the formulation of a perioperative care bundle 'POPC-CB' intended to reduce the incidence of POPC. The POPC-CB was designed to be applied in addition to, rather than replacing, enhanced recovery pathways in patients at moderate to high risk of POPC.

\section{Methods}

We performed a survey of members of the European Society of Intensive Care Medicine (ESICM) Perioperative Intensive Care (POIC) section, both to identify 'expert volunteers' for the Delphi and to gain an appreciation of clinical opinion regarding the potential components of a POPC-CB. From a survey sent to the 6623 members of the POIC group of ESICM, there were 362 responses which helped establish the potential of POPC risk assessments and possible interventions in a POPC-CB for patients screened at moderate to high risk. One hundred thirty-four experts were identified during this process, and they were invited to collaborate with the project. Additionally, 41 authors from key literature on the subject were invited to participate and 38 experts agreed to form the consensus group.

Three rounds of questions were anonymously circulated to the Delphi group via email with a 2-week deadline for responses to each round. The questions comprised a series of statements which the experts were asked to respond to using a 5-point Likert scale alongside free text spaces for comments and references to relevant publications. Some rounds included more open-ended questions and a ranking system for a preferred option. If an expert wanted to skip a question, the response box would be left blank. After each round, the project coordinators collated the results of the round and feedback of themes was given to the group. By the end of the process, the final feedback was sent to the group, this time not anonymised, with the consensus and a suggested care bundle. 


\section{Results}

\section{Survey}

Three hundred sixty-two members of the POIC group participated in the initial survey. Routine screening for POPC risk occurred in 50\% of centres, with varying POPC reduction techniques available (Appendices 1 and 2). Seventy-eight percent of respondents specified that they would be happy to participate in developing and assessing the implementation of a POPC-CB.

\section{Delphi}

Three rounds of the Delphi were circulated; in total, 35 experts responded to at least one round with 21 replying to all rounds. Two experts who expressed interest in being involved in the project did not reply to any of the rounds, and one expert withdrew from the consensus.

POPC encompasses a range of clinical syndromes (i.e. respiratory failure) and diagnoses (i.e. pneumothorax), and there are limitations in having this as an endpoint. However, there was a strong consensus (>90\% strongly agreeing (SA) or agreeing (A)) that reduction in $\mathrm{POPC}$ as a composite was the goal of the CB. There was a strong consensus (28/29, 97\%) that the POPC-CB should be applied to higher-risk patients (as opposed to all patients) and include pre-, intra- and post-operative components in addition to standard enhanced recovery elements (100\%). There was no consensus on the minimum required specific interventions that any patient should receive in order for them to have consider to have been treated within an ERAS pathway. ERAS implementation varies between centres and between types of surgery. It was acknowledged that various methods can be used to identify patients at higher risk of POPC and the ARISCAT score was the most widely recognised validated screening tool. Less popular were the Arozullah (Arozullah et al. 2000) and Gupta methods (Gupta et al. 2011). It was agreed to design the POPC-CB without cost being a major consideration.

Following a round whereby we gained information about what types of intervention were favoured during each perioperative stage, we progressed to better refining which components were the most favoured (Table 1). There was a weak consensus that seven was the optimal number of components in the POPC-CB.

\section{Discussion}

We used a Delphi process to design a care bundle (POPC-CB), for patients at moderate to high risk of post-operative pulmonary complications which may have the potential to improve clinical outcomes. The proposed interventions are implemented throughout the perioperative journey: prior to the operation, supervised exercise programme and inspiratory muscle training, and during the operation, low tidal volume ventilation with individualised PEEP, use of routine monitoring to avoid hyperoxia and efforts made to limit neuromuscular blockade, and also post-operatively, deep breathing exercises and mandatory elevation of the head of the bed.

The quality and extent of clinical evidence to support each of the proposed components of the POPC-CB is variable. The Delphi process did not involve a formal evaluation of the strength of evidence for the interventions included in the care bundle, nor for those that were rejected. Some of the individual interventions have been evaluated by

Table 1 Table to demonstrate the components included in the CB and those which were not chosen by the Delphi consensus

\begin{tabular}{|c|c|c|c|}
\hline & Pre-operative & Intra-operative & Post-operative \\
\hline $\begin{array}{l}\text { In the care } \\
\text { bundle }\end{array}$ & $\begin{array}{l}\text { - Supervised exercise programme } \\
\text { - Inspiratory muscle training }\left(^{*}\right)\end{array}$ & $\begin{array}{l}\text { - Low tidal volume ventilation }\left(^{* *}\right) \text { with } \\
\text { individualised PEEP } \\
\text { - Use of routine monitoring to avoid hyperoxia } \\
\text { - Limit NM blockade }\end{array}$ & $\begin{array}{l}\text { - Deep breathing exercises } \\
\text { - Mandatory elevation of the head } \\
\text { of the bed }\end{array}$ \\
\hline $\begin{array}{l}\text { Not in } \\
\text { the care } \\
\text { bundle }\end{array}$ & $\begin{array}{l}\text { - Oropharyngeal decontamination } \\
\text { - Oral care package } \\
\text { - Chlorhexidine mouthwash } \\
\text { or other selective oral } \\
\text { decontamination } \\
\text { - Selective digestive } \\
\text { decontamination } \\
\text { - Incentive spirometry } \\
\text { - Deep breathing exercises } \\
\text { - Daily pedometer targets }\end{array}$ & $\begin{array}{l}\text { - Recruitment manoeuvres } \\
\text { - Routine use of high levels of PEEP } \\
\text { - Use of endotracheal tubes with specific design } \\
\text { features, including subglottic secretion drainage } \\
\text { - Specific drugs or techniques to limit residual } \\
\text { neuromuscular blockade }\end{array}$ & $\begin{array}{l}\text { - Prophylactic ventilator support including } \\
\text { CPAP, NIV or high-flow nasal oxygen } \\
\text { - Pharmacological therapies that aim to } \\
\text { decrease gastro-oesophageal reflux }\end{array}$ \\
\hline
\end{tabular}


others using GRADE or Jadad methodologies (Guyatt et al. 2011; Jadad et al. 1996). A Cochrane review of preoperative inspiratory muscle training demonstrated efficacy at reducing POPC (Katsura et al. 2015). Using GRADE criteria, the Cochrane reviewers suggested the strength of evidence for pneumonia reduction was moderate whilst the strength of evidence for atelectasis and adverse event reduction was low and recommended caution due to the potential for overestimation of treatment effect. Although our Delphi process supports the inclusion of supervised preoperative exercise programme, the evidence for improved postoperative clinical outcomes is limited (O'Doherty et al. 2013). A meta-analysis of nine prehabilitation trials in 435 abdominal surgery patients suggests that supervised exercise can reduce overall postoperative complications, and five of these studies specifically demonstrated a reduction in postoperative pulmonary complications (Moran et al. 2016). A very low quality rating was observed using GRADE criteria due to the small sample sizes and significant risk of bias. Furthermore, the precise components of such a supervised programme have not been fully evaluated in relation to POPC reduction.

Protective lung ventilation strategies incorporating tidal volumes $5-8 \mathrm{~mL} / \mathrm{kg}$, higher PEEP and control of plateau pressure are beneficial in critically ill patients with acute lung injury or ARDS (Villar et al. 2006; Petrucci and Iacovelli 2007). In ICU patients without ARDS, a protective lung strategy reduced pulmonary and systemic inflammation and reduced the development of lung injury (Determann et al. 2010). A meta-analysis of 20 studies, using GRADE criteria, suggested the evidential strength for protective lung strategy in patients without ARDS to be moderate and high in reducing lung injury and mortality, respectively, but low in preventing pneumonia (Neto et al. 2012). These findings from critical care patients led to perioperative research exploring whether protective lung ventilation has a role during major surgery. The IMPROVE trial compared a 'protective' strategy of tidal volume $6-8 \mathrm{~mL} / \mathrm{kg}$ ideal body weight, PEEP $6-8 \mathrm{~cm} \mathrm{H}_{2} \mathrm{O}$, recruitment manoeuvers every $30 \mathrm{~min}$ with 'conventional' management of tidal volume $10-12 \mathrm{~mL} / \mathrm{kg}$, and PEEP and recruitment manoeuvers at clinicians' discretion. The protective strategy was associated with a reduction in a composite of pulmonary and septic complications (Futier et al. 2013a). In another trial, PROVHILO, all patients received tidal volumes $8 \mathrm{~mL} / \mathrm{kg}$ and were randomly assigned to either rather high PEEP of 12 and regular recruitment manoeuvers or to low PEEP 0-2. The result shows no difference in post-operative pulmonary complications but shows increased adverse events in the high PEEP group (Prove Network Investigators for the Clinical Trial Network of the European Society of Anaesthesiology et al. 2014). Even in critically ill ventilated ARDS patients, high versus very high PEEP levels was not shown to influence outcome (Brower et al. 2004). A meta-analysis of 15 studies investigating protective lung ventilation involving 2127 surgical patients concluded that intraoperative low tidal volume is associated with less pulmonary complications but no difference in mortality and length of hospital stay (Neto et al. 2015). The authors used the Jadad criteria to rate the quality of this evidence with seven studies scoring $4 / 5$, seven $3 / 5$ and one 2/5. Our Delphi consensus suggests low tidal volumes for all patients with individualised PEEP and recruitment manoeuvres at the discretion of the attending anaesthetist.

Inadequate reversal of neuromuscular blockade is associated with POPC. Post-operative residual curarization (PORC) is the incomplete recovery of muscle function following perioperative use of neuromuscular blocking agents. The prevalence of PORC is anything between 4 and $45 \%$, when defined as train-of-four $<0.9$ and is associated with adverse outcomes including POPC (Berg et al. 1997). Whilst the Delphi consensus recommendation is to limit neuromuscular blockade by careful monitoring of neuromuscular function and effective reversal, we acknowledge that ongoing research assessing the impact of neuromuscular blockade on POPC is awaiting publication and no specific drug or technique can be recommended. The potential for hyperoxia to cause harm is contentious. The association between hyperoxia and atelectasis is well established, although the magnitude of this effect may be overestimated (Pryor et al. 2004). A metaanalysis of 17 randomised controlled trials with 8093 mixed surgical patients used the Jadad score to assess quality and found six studies scored $5 / 5$, four $4 / 5$ and 7 less than 4 , with sub-group analysis suggesting that hyperoxia can reduce surgical site infection in colorectal surgery patients (Yang et al. 2016).

Post-operative care from a specialist physiotherapist is a commonplace; however, the interventions delivered by physiotherapists vary significantly, and there is a scarcity of good-quality clinical evidence to inform practice with many small, underpowered studies using inadequate randomisation and unclear interventions (ÖRman and Westerdahl 2010; Pasquina et al. 2006). The incremental benefit of the proposed deep breathing exercises is uncertain, 
particularly when other aspects of post-operative physiotherapy, such as early mobilisation, are provided (Mackay et al. 2005). A Cochrane review of post-operative incentive spirometry following upper abdominal surgery described a small number of poor-quality studies which were unable to demonstrate any effect on postoperative complications (do Nascimento Junior et al. 2014). Elevation of the head of the bed, allowing gravity to help minimise pulmonary aspiration of oropharyngeal secretions and perhaps improve effectiveness of coughing, has been shown to reduce ventilatorassociated pneumonia in critically ill patients although no evidence is available in POPC reduction (Wang et al. 2016).

I COUGH, a post-operative pulmonary care bundle, demonstrated a trend towards reduction in POPC (Cassidy et al. 2013). I COUGH incorporates Incentive spirometry, Coughing and deep breathing, Oral hygiene, Understanding (patient education), Get up (mobilisation) and Head of bed elevation. I COUGH was applied to all patients, not just those at high risk of POPC, and it was evaluated in a single centre and was evaluated prior to widespread adoption of enhanced recovery pathways. Our POPC-CB is designed to supplement established guidelines for enhanced recovery, not replace them (Lassen et al. 2009; ERAS society guidelines n.d.). Although this protocol is designed for all patients undergoing major surgery, elements of ERAS pathways are relevant to reducing the incidence of POPC. These include optimal analgesia, avoidance of nasogastric tubes and bowel preparation, minimisation of 'nil by mouth', avoidance of sodium and water overload, routine early post-operative mobilisation, multi-modal analgesia and prevention of nausea and vomiting. A quality improvement programme incorporating ICOUGH into ERAS pathways has reduced POPC over time (Moore et al. 2017).

\section{Strengths and limitations}

An expert consensus using Delphi techniques is fundamentally dissimilar to a systematic review of evidence, and this is both a strength and a weakness. We made no attempt to inform or influence the experts, and the POPC-CB reflects opinions not necessarily supported by clinical evidence. Several components in this proposed CB have been the subject of detailed studies whilst others such as high-flow nasal oxygen and continuous positive airway pressure are under evaluation (Futier et al. 2013b). Conversely, some interventions that were considered but not selected for the POPC-CB have good evidence of clinical efficacy such as perioperative oral decontamination (Spreadborough et al. 2016).

During the Delphi process, 'avoiding hyperoxia' (excessively high partial pressure of oxygen, measured directly or detected from pulse oximetry) as an intra-operative component proved controversial leading to one expert withdrawing from the consensus amid concerns that some clinicians may misinterpret this component as 'permissive hypoxaemia' or avoidance of high inspired oxygen during critical airway interventions such as intubation. We believe that avoiding hypoxaemia is a fundamental part of anaesthetic management and therefore should not require inclusion within the $\mathrm{POPC}-\mathrm{CB}$.

\section{Research recommendations}

Prior to an evaluation of the clinical effectiveness of this POPC-CB, it is necessary to gain more information about the uptake of enhanced recovery programmes and, more specifically, the feasibility of undertaking this study. Only $50 \%$ of survey respondents screen patients for POPC risk, and a consistent screening of all patients needs to be implemented. Consistent delivery of all aspects of the care bundle will need to be specified, for example, what is meant by 'supervised exercise programme'. It is uncertain to what extent these measures are part of routine clinical practice. Recent data from the UK suggest that protective lung ventilation in major open abdominal surgery is rarely used (Patel et al. 2016). Robust collection of postoperative outcome data, using standardised measures, is essential, and this may require additional local resources (Myles et al. 2016). Alternatively, large databases of surgical patients could potentially relate provision of POPC-CB components to the incidence of POPC.

\section{Conclusion}

Patients at moderate to high risk of POPC, undergoing major elective surgery within an enhanced recovery programme, can be identified using screening tools such as the ARISCAT score and may benefit from a care bundle aimed at reducing these complications such as that described during our Delphi process. We believe a multi-centre international evaluation of the efficacy of such a care bundle in reducing the incidence of $\mathrm{POPC}$, length of stay and long-term outcomes should be a priority for research in perioperative care. 


\section{Appendix 1}

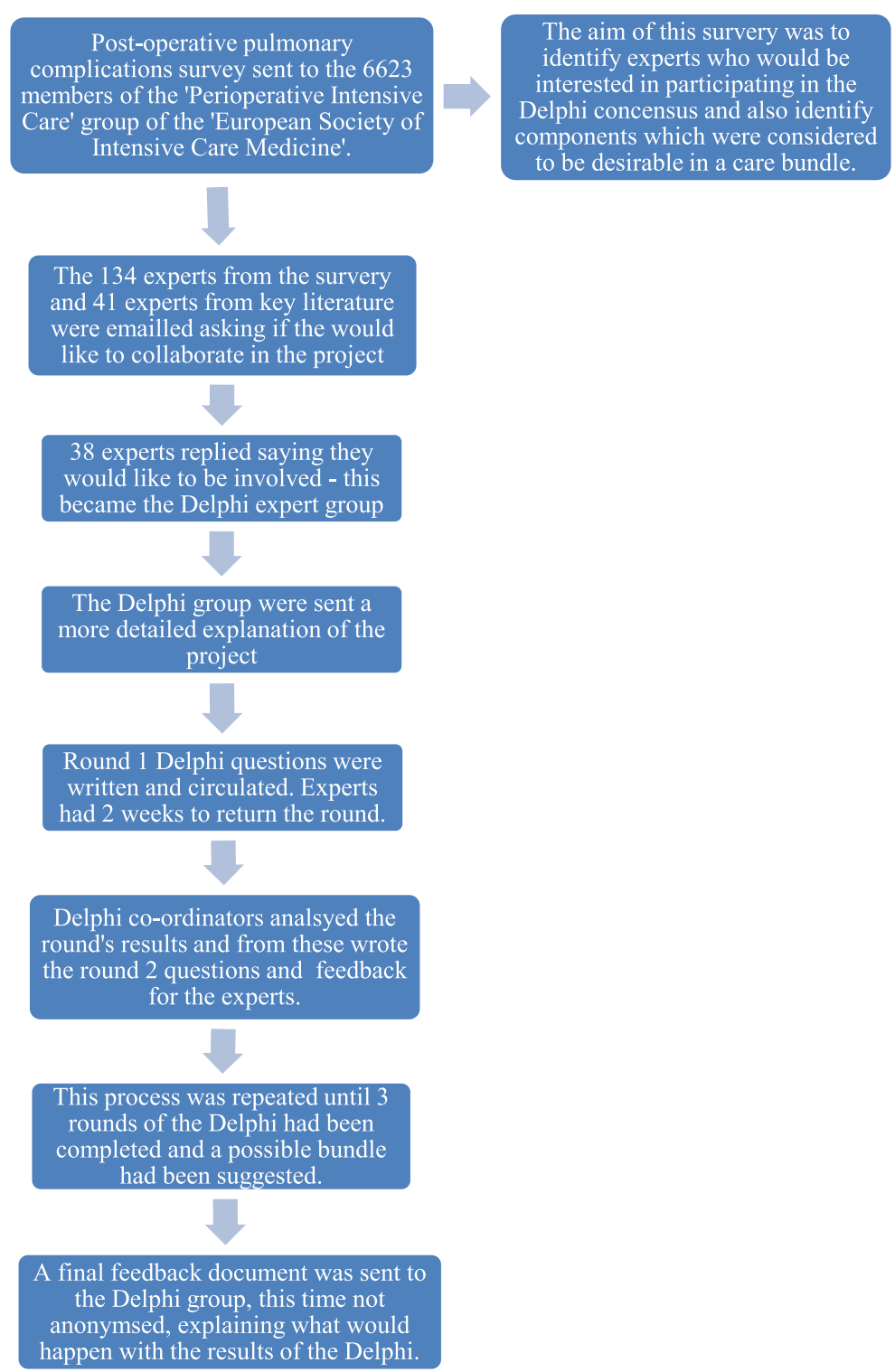

Fig. 1 Flow diagram to summarise the methods 
Appendix 2

\section{Results of the POPC survey of the POIC group of the ESICM}

POIC group (http://www.esicm.org/sections/perioperative-intensive-care) is a special interest section for members of the European Society of Intensive Care Medicine (ESICM). There are 6623 members and a link to a survey monkey was emailed to them during October 2015. There were 362 responses (5.5\%).

\begin{tabular}{|c|c|c|}
\hline \multicolumn{3}{|c|}{$\begin{array}{l}\text { Question 1: In your institution, is it routine to screen patients } \\
\text { undergoing surgery to identify those at high risk for POPC? }\end{array}$} \\
\hline Answer options & Response count & Response percentage (\%) \\
\hline Yes & 174 & 48.7 \\
\hline No & 183 & 51.3 \\
\hline
\end{tabular}

Question 2: If institutions were to routinely screen for patients at high risk for POPC and then provide a POPC reduction care bundle, what recommendations would you make for constituents of this care bundle? To be applied PRE-operatively:

\begin{tabular}{|c|c|c|}
\hline Answer options & $\begin{array}{l}\text { Response } \\
\text { count }\end{array}$ & $\begin{array}{l}\text { Response } \\
\text { percentage (\%) }\end{array}$ \\
\hline Chlorhexidine mouthwash & 155 & 50.5 \\
\hline $\begin{array}{l}\text { Selective oral decontamination (SOD), e.g. } \\
\text { anti-microbial paste }\end{array}$ & 34 & 11.1 \\
\hline $\begin{array}{l}\text { Selective digestive decontamination (SDD), } \\
\text { e.g. non-absorbable enteral antibiotics and } \\
\text { IV antibiotics }\end{array}$ & 24 & 7.8 \\
\hline $\begin{array}{l}\text { Oral care, e.g. toothbrushing, } \\
\text { dental hygienist review etc. }\end{array}$ & 147 & 47.9 \\
\hline $\begin{array}{l}\text { Supervised exercise programme, } \\
\text { also known as pre-habilitation }\end{array}$ & 140 & 45.6 \\
\hline Nebulised/inhaled medical therapy & 94 & 30.6 \\
\hline Enteral/intravenous medical therapy & 39 & 12.7 \\
\hline $\begin{array}{l}\text { Incentive spirometry or positive } \\
\text { end-expiratory pressure valve }\end{array}$ & 197 & 64.2 \\
\hline Inspiratory muscle training & 169 & 55.0 \\
\hline
\end{tabular}

Question 3: If institutions were to routinely screen for patients at high-risk for POPC and then provide a POPC-reduction care bundle, what recommendations would you make for constituents of this care bundle? To be applied INTRA-operatively:

\begin{tabular}{lll}
\hline Answer options & $\begin{array}{l}\text { Response } \\
\text { count }\end{array}$ & $\begin{array}{l}\text { Response } \\
\text { percentage (\%) } \\
\text { Low tidal volume ventilation, }\end{array}$ \\
$\begin{array}{l}\text { e.g. 6-8 mL/kg tidal volumes } \\
\text { Appropriate PEEP }\end{array}$ & 286.6 \\
$\begin{array}{l}\text { Regular recruitment manoeuvres } \\
\text { Endotracheal tube with subglottic }\end{array}$ & 141 & 74.3 \\
$\begin{array}{l}\text { secretion drainage } \\
\text { Nebulised antibiotics }\end{array}$ & 101 & 29.9 \\
$\begin{array}{l}\text { Avoid blood transfusion by tolerating } \\
\text { anaemia unless Hb } \leq 70 \text { g/L }\end{array}$ & 193 & 57.1 \\
$\begin{array}{l}\text { Use humidified ventilator circuit } \\
\begin{array}{l}\text { Avoid neuromuscular blockade (NMB) } \\
\text { other than short-acting NMB for intubation }\end{array}\end{array}$ & 182 & 53.8 \\
\end{tabular}

(Continued)

Question 3: If institutions were to routinely screen for patients at high-risk for POPC and then provide a POPC-reduction care bundle, what recommendations would you make for constituents of this care bundle? To be applied INTRA-operatively:

\begin{tabular}{lcc}
\hline $\begin{array}{l}\text { Specific methods to evaluate or } \\
\text { reverse NMB }\end{array}$ & 117 & 34.6 \\
$\begin{array}{l}\text { Fluid resuscitation using advanced } \\
\text { monitoring (EVLWI or lung US) to } \\
\text { avoid pulmonary oedema }\end{array}$ & 147 & 43.5 \\
$\begin{array}{l}\text { Avoid hyperoxia (saturations } \geq 99 \% \\
\text { or } \mathrm{PaO}_{2} \geq 14 \mathrm{kPa} \text { ) }\end{array}$ & 206 & 60.9 \\
\begin{tabular}{l} 
Anti-sialogogues, e.g. glycopyrronium \\
\hline
\end{tabular} & 40 & 11.8 \\
\hline
\end{tabular}

Question 4: If institutions were to routinely screen for patients at high risk for POPC and then provide a POPC-reduction care bundle, what recommendations would you make for constituents of this care bundle? To be applied POST-operatively:

\begin{tabular}{lll}
\hline Answer options & $\begin{array}{l}\text { Response } \\
\text { count }\end{array}$ & $\begin{array}{l}\text { Response } \\
\text { percentage (\%) }\end{array}$ \\
$\begin{array}{l}\text { High-flow humidified oxygen via } \\
\text { nasal cannulae }\end{array}$ & 158 & 46.3 \\
$\begin{array}{l}\text { CPAP administered via facemask or hood } \\
\text { Extubation directly onto bi-level positive } \\
\text { pressure ventilation via face mask in } \\
\text { all patients }\end{array}$ & 38 & 51.0 \\
$\begin{array}{l}\text { Extubation directly onto bi-level positive } \\
\text { pressure ventilation via face mask in } \\
\text { selected patients }\end{array}$ & 105 & 30.8 \\
$\begin{array}{l}\text { Incentive spirometry/regular use of } \\
\text { positive end-expiratory pressure valve }\end{array}$ & 187 & 54.8 \\
$\begin{array}{l}\text { Inspiratory muscle training } \\
\begin{array}{l}\text { Specific physical therapy or exercises, } \\
\text { additional to ERAS early mobilisation }\end{array}\end{array}$ & 147 & 47.5 \\
$\begin{array}{l}\text { Avoid use of gastric acid } \\
\text { suppression medications } \\
\text { Head of bed elevation }\end{array}$ & 96 & 28.2 \\
$\begin{array}{l}\text { Mini-tracheostomy to permit suctioning } \\
\text { of airway secretions }\end{array}$ & 13 & 3.8 \\
$\begin{array}{l}\text { Avoidance of hyperoxia (saturations } \geq 99 \% \\
\text { or PaO } 2 \text { 14 kPa) }\end{array}$ & 194 & 56.9 \\
\hline
\end{tabular}

Question 5: Would you potentially be interested in assessing the feasibility of using this care bundle approach in patients who are at high risk of POPC in your institution?

\begin{tabular}{lll}
\hline Answer options & Response count & Response percentage (\%) \\
Yes & 242 & 79.1 \\
No & 64 & 20.9 \\
\hline
\end{tabular}

Question 6: Once feasibility has been assessed, might your institution be interested in participating in an international multi-centre clinical trial assessing the effectiveness of a POPC reduction care bundle?

\begin{tabular}{lll}
\hline Answer options & Response count & Response percentage (\%) \\
Yes & 239 & 78.1 \\
No & 67 & 21.9 \\
\hline
\end{tabular}




\section{Acknowledgements}

The POPC-CB investigators:

Belda, F. Javier

Department of Surgery, University of Valencia, Valencia, Spain

Blobner, Manfred

Klinik für Anaesthesiologie

Technische Universität München

München

Blot, Stijn

Dept. of Internal Medicine, Ghent University, Ghent, Belgium and Burns

Trauma \& Critical Care Research Centre, The University of Queensland,

Brisbane, Australia

Bugedo, Guillermo

Professor, Department of Intensive Care Medicine

Pontificia Universidad Catolica de Chile

Cabrini, Luca MD

Department of Anaesthesia and Intensive Care

Ospedale Istituto Scientifico San Raffaele, Milan, Italy

Canet, Jaume PhD

Chief of Department of Anaesthesiology

Hospital Universitari Germans Trias i Pujol

Barcelona, Spain

Chiumello, Davide

Dipartimento di Anestesia, Rianimazione ed Emergenza-Urgenza, Fondazione

IRCCS Ca' Granda - Ospedale Maggiore Policlinico, Milano, Italy

Engoren, Milo MD

Department of Anesthesiology

University of Michigan

Gallart, Lluis Tenured Professor

Department of Anesthesiology, Hospital del Mar. IMIM. Universitat Autonoma

de Barcelona, Barcelona

G. Cosío, Borja MD, PhD

Director, Research Unit

Department of Respiratory Medicine

Hospital Universitario Son Espases

Spain

Guérin, Claude

University of Lyon and INSERM 955 Créteil, France

Jachymiak, Izabela

Department of Anesthesiology and Intensive Care - Podhalański Specialist

Hospital. Pope John Paul II in Nowy Targ

Jammer, lb

Department of Clinical Medicine, University of Bergen, Bergen, Norway

Department of Anaesthesiology and Intensive Care, Haukeland University Hospital, Bergen, Norway

Lamas, Cristiane da Cruz MD MRCP PhD

Instituto Nacional de Cardiologia and Unigranrio, Rio de Janeiro, Brazil

Makowski, Arystarch MD, PhD

Consultant in Anaesthesia and Critical Care

Medway NHS Foundation Trust

Malbouisson, Luiz Marcelo MD, PhD

Divisão de Anestesiologia

Hospital das Clínicas da Faculdade de Medicina da Universidade de São Paulo Matamis, D

ICU Head

Papageorgiou Hospital, Thessaloniki, Greece

Moonesinghe, Ramani

FRCA MRCP FFICM MD (Res)

Consultant in Anaesthesia and Intensive Care Medicine, UCLH

Hon Senior Lecturer in Anaesthesia, UCL

Moore, John

Clinical Director

Adult Critical care

Manchester Royal Infirmary

Mythen, Monty MBBS MD FRCA FFICM FCAI (Hon)

Smiths Medical Professor of Anaesthesia and Critical Care, University College London

Paugam-Burtz, C

Departement of Anesthesiology and perioperative care medicine

Hôpital Beaujon, HUPNVS APHP

Pearse, Rupert MD FRCA FFICM
NIHR Research Professor \& Consultant in Intensive Care Medicine

Queen Mary University of London

Pelosi, Paolo MD, FERS

Department of Surgical Sciences and Integrated Diagnostics, IRCCS AOU San

Martino IST, University of Genoa, Genoa, Italy

Poelaert, Jan MD, PhD

Chair and Director

Department of Anesthesiology and Perioperative Medicine; Acute and

Chronic Pain Therapy

Universitair Ziekenhuis Brussel

Ponssen, Huibert MD

Albert Schweitzer Hospital, Dordrecht, the Netherlands

Department: Intensive Care

Rasmussen, Bodil Steen

Professor, MD, PhD

Department of Anaesthesia and Intensive Care Medicine

Aalborg University Hospital

Sander, Michael

Department of Anaesthesiology, Intensive Care Medicine and Pain Therapy

University Hospital Gießen and Marburg GmbH

Justus-Liebig-Universität Gießen

Schuerer, Douglas MD, FACS, FCCM

Washington University School of Medicine

Department of Surgery, St. Louis, MO

Smetana, Gerald W. M.D.

Division of General Medicine and Primary Care

Beth Israel Deaconess Medical Center, Boston

Professor of Medicine

Harvard Medical School

Summers, Charlotte BSC BM PhD MRCP FFICM

University Lecturer in Intensive Care Medicine

Division of Anaesthesia

University of Cambridge School of Clinical Medicine

Addenbrooke's Hospital

Talmor, Daniel MD, MPH

Department of Anesthesia, Critical Care, and Pain Medicine

Beth Israel Deaconess Medical Center and Harvard Medical School

Valkenet, Karin

UMC Utrecht in Action and Coördinating researcher PREPARE study, Dep.

Rehabilitation, Nursing Science \& Sport, University Medical Center Utrecht,

The Netherlands

Veličković, Jelena MD

Clinical Centre of Serbia, Belgrade, Serbia

University of Belgrade, School of Medicine

Vincent, Jean-Louis

Professor of Intensive Care Medicine (Université Libre de Bruxelles)

Dept of Intensive Care, Erasme Univ Hospital

President, World Federation of Societies of Intensive and Critical Care

Medicine (WFSICCM)

Wren, Sherry M. MD, FACS

Professor of Surgery

Stanford University School of Medicine

\section{Funding}

None.

Availability of data and materials

The data used in this study are available. A summary is included in Appendices 1 and 2.

\section{Authors' contributions}

SVG conducted the Delphi consensus, BCCB and MPWG designed the Delphi and all authors helped in interpreting the results and both read and approved the final manuscript.

Ethics approval and consent to participate

Not applicable.

\section{Consent for publication}

Not applicable. 


\section{Competing interests}

The authors declare that they have no competing interests.

\section{Publisher's Note}

Springer Nature remains neutral with regard to jurisdictional claims in published maps and institutional affiliations.

\section{Author details}

'Faculty of Medicine, University of Southampton, Southampton SO16 6YD, UK. ${ }^{2}$ Department of Anaesthesia and Critical Care, Central Manchester Foundation Trust, M13 9WL, Manchester, UK. ${ }^{3}$ Department of Anaesthesiology, Intensive Care Medicine and Pain Therapy, University Hospital Gießen, Giessen, Germany. ${ }^{4}$ Department of Anaesthesiology and Intensive Care, Haukeland University Hospital, Bergen, Norway. ${ }^{5}$ Department of Clinical Medicine, University of Bergen, Bergen, Norway. ${ }^{6} \mathrm{Critical}$ Care Research Group, Southampton NIHR Biomedical Research Centre, Southampton University Hospitals NHS Trust/University of Southampton, Southampton SO16 6YD, UK. 'Intensive Care Unit, Royal Surrey County Hospital, Guildford GU2 7XX, UK. ${ }^{8}$ Surrey Perioperative Anaesthetic Critical care collaborative group (SPACeR), FHMS, University of Surrey, Guildford GU2 $7 \mathrm{XH}, \mathrm{UK}$

\section{Received: 12 April 2017 Accepted: 14 February 2018}

Published online: 17 April 2018

\section{References}

Arozullah AM, Daley J, Henderson WG, Khuri SF, Program NVASQI. Multifactorial risk index for predicting postoperative respiratory failure in men after major noncardiac surgery. Annals of Surg. 2000;232:242-53.

Berg H, Viby-Mogensen J, Roed J, Mortensen C, Engbæk J, Skovgaard LT, Krintel J. Residual neuromuscular block is a risk factor for postoperative pulmonary complications. A prospective, randomised, and blinded study of postoperative pulmonary complications after atracurium, vecuronium and pancuronium. Acta Anaesthesiol Scand. 1997;41:1095-103.

Brower R, Lanken P, Maclntyre N, Matthay M, Morris A, Ancukiewicz M, Schoenfeld D, Thompson B. Higher versus lower positive end-expiratory pressures in patients with the acute respiratory distress syndrome. N Engl J Med. 2004;351:327.

Canet J, Gallart L, Gomar C, Paluzie G, Valles J, Castillo J, Sabate S, Mazo V, Briones Z, Sanchis J, Group A. Prediction of postoperative pulmonary complications in a population-based surgical cohort. Anesthesiology. 2010;113:1338-50.

Canet J, Sabate S, Mazo V, Gallart L, de Abreu MG, Belda J, Langeron O, Hoeft A, Pelosi P, group P. Development and validation of a score to predict postoperative respiratory failure in a multicentre European cohort: a prospective, observational study. Eur J Anaesthesiol. 2015;32:458-70.

Cassidy MR, Rosenkranz P, McCabe K, Rosen JE, McAneny D. I COUGH: reducing postoperative pulmonary complications with a multidisciplinary patient care program. JAMA Surg. 2013;148:740-5.

Dalkey N, Helmer O. An experimental application of the Delphi method to the use of experts. Manag Sci. 1963;9:458-67.

Determann RM, Royakkers A, Wolthuis EK, Vlaar AP, Choi G, Paulus F, Hofstra J-J, de Graaff MJ, Korevaar JC, Schultz MJ. Ventilation with lower tidal volumes as compared with conventional tidal volumes for patients without acute lung injury: a preventive randomized controlled trial. Crit Care. 2010;14:R1.

do Nascimento Junior P, Modolo NS, Andrade S, Guimaraes MM, Braz LG, El Dib R. Incentive spirometry for prevention of postoperative pulmonary complications in upper abdominal surgery. Cochrane Libr. 2014; Issue 2. Art. No.: CD006058. https://doi.org/10.1002/14651858.CD006058.pub3

ERAS society guidelines. http://erassociety.org/quidelines/list-of-quidelines/. Accessed 8 Mar 2018.

Fernandez-Bustamante A, Frendl G, Sprung J, Kor DJ, Subramaniam B, Ruiz RM, Lee J-W, Henderson WG, Moss A, Mehdiratta N. Postoperative pulmonary complications, early mortality, and hospital stay following noncardiothoracic surgery: a multicenter study by the perioperative research network investigators. JAMA Surg. 2017;152:157-66.

Futier E, Constantin JM, Paugam-Burtz C, Pascal J, Eurin M, Neuschwander A, Marret E, Beaussier M, Gutton C, Lefrant JY, et al. A trial of intraoperative low-tidalvolume ventilation in abdominal surgery. N Engl J Med. 2013b;369:428-37.

Futier E, Paugam-Burtz C, Constantin J-M, Pereira B, Jaber S. The OPERA trial-comparison of early nasal high flow oxygen therapy with standard care for prevention of postoperative hypoxemia after abdominal surgery: study protocol for a multicenter randomized controlled trial. Trials. 2013a;14:341.

Gupta H, Gupta PK, Fang X, Miller WJ, Cemaj S, Forse RA, Morrow LE. Development and validation of a risk calculator predicting postoperative respiratory failure. CHEST J. 2011;140:1207-15.

Guyatt GH, Oxman AD, Schünemann HJ, Tugwell P, Knottnerus A. GRADE guidelines: a new series of articles in the Journal of Clinical Epidemiology. $J$ Clin Epidemiol. 2011;64:380-2.

Jadad AR, Moore RA, Carroll D, Jenkinson C, Reynolds DJM, Gavaghan DJ, McQuay HJ. Assessing the quality of reports of randomized clinical trials: is blinding necessary? Control Clin Trials. 1996;17:1-12.

Katsura M, Kuriyama A, Takeshima T, Fukuhara S, Furukawa TA. Preoperative inspiratory muscle training for postoperative pulmonary complications in adults undergoing cardiac and major abdominal surgery. Cochrane Libr. 2015;

Khuri SF, Henderson WG, DePalma RG, Mosca C, Healey NA, Kumbhani DJ, Participants in the VANSQIP. Determinants of long-term survival after major surgery and the adverse effect of postoperative complications. Ann Surg. 2005;242:326-41.

Lassen K, Soop M, Nygren J, Cox PBW, Hendry PO, Spies C, von Meyenfeldt MF, Fearon KC, Revhaug A, Norderval S. Consensus review of optimal perioperative care in colorectal surgery: Enhanced Recovery After Surgery (ERAS) group recommendations. Arch Surg. 2009:144:961-9.

Lee C-Z, Kao L-T, Lin H-C, Wei P-L. Comparison of clinical outcome between laparoscopic and open right hemicolectomy: a nationwide study. World J Surg Oncol. 2015;13:250.

Ljungqvist O, Scott M, Fearon KC. Enhanced recovery after surgery: a review. JAMA Surg. 2017;152:292-8

Mackay MR, Ellis E, Johnston C. Randomised clinical trial of physiotherapy after open abdominal surgery in high risk patients. Aust J Physiother. 2005;51:151-9.

Moore J, Conway D, Thomas N, Cummings D, Atkinson D. Impact of a perioperative quality improvement programme on postoperative pulmonary complications. Anaesthesia. 2017;72:317-27.

Moran J, Guinan E, McCormick P, Larkin J, Mockler D, Hussey J, Moriarty J, Wilson F. The ability of prehabilitation to influence postoperative outcome after intra-abdominal operation: a systematic review and meta-analysis. Surgery. 2016;160:1189-201.

Myles P, Grocott M, Boney O, Moonesinghe S, Myles P, Grocott M, Biccard B, Boney O, Chan M, Fleisher L. Standardizing end points in perioperative trials: towards a core and extended outcome set. Br J Anaesth. 2016;1 16:586-9.

Neto AS, Cardoso SO, Manetta JA, Pereira VGM, Espósito DC, Pasqualucci MOP, Damasceno MCT, Schultz MJ. Association between use of lung-protective ventilation with lower tidal volumes and clinical outcomes among patients without acute respiratory distress syndrome: a meta-analysis. JAMA. 2012;308:1651-9

Neto AS, Hemmes SN, Barbas CS, Beiderlinden M, Biehl M, Binnekade JM, Canet J, Fernandez-Bustamante A, Futier E, Gajic O. Protective versus conventional ventilation for surgery: a systematic review and individual patient data meta-analysis. Anesthesiol. 2015;123:66-78.

O'Doherty A, West M, Jack S, Grocott M. Preoperative aerobic exercise training in elective intra-cavity surgery: a systematic review. $\mathrm{Br} J$ Anaesth. 2013:110:679-89.

ÖRman J, Westerdahl E. Chest physiotherapy with positive expiratory pressure breathing after abdominal and thoracic surgery: a systematic review. Acta Anaesthesiol Scand. 2010;54:261-7.

Pasquina $\mathrm{P}$, Tramèr MR, Granier J-M, Walder B. Respiratory physiotherapy to prevent pulmonary complications after abdominal surgery: a systematic review. CHEST J. 2006:130:1887-99.

Pasquina P, Walder B. Prophylactic respiratory physiotherapy after cardiac surgery: systematic review. BMJ. 2003:327:1379.

Patel JM, Baker R, Yeung J, Small C. Intra-operative adherence to lung-protective ventilation: a prospective observational study. Perioper Med. 2016;5:1-8.

Pecorelli N, Hershorn O, Baldini G, Fiore JF, Stein BL, Liberman AS, Charlebois P, Carli F, Feldman LS. Impact of adherence to care pathway interventions on recovery following bowel resection within an established enhanced recovery program. Surg Endosc. 2017;31:1760-71.

Petrucci $\mathrm{N}$, lacovelli W. Lung protective ventilation strategy for the acute respiratory distress syndrome. Cochrane Database Syst Rev. 2007;3 Art. No: CD003844. https://doi.org/10.1002/14651858.CD003844.pub4.

Prove Network Investigators for the Clinical Trial Network of the European Society of Anaesthesiology, Hemmes SN, Gama de Abreu M, Pelosi P, Schultz $\mathrm{MJ}$. High versus low positive end-expiratory pressure during general anaesthesia for open abdominal surgery (PROVHILO trial): a multicentre randomised controlled trial. Lancet. 2014;384:495-503. 
Pryor KO, Fahey IIIT, Lien CA, Goldstein PA. Surgical site infection and the routine use of perioperative hyperoxia in a general surgical population: a randomized controlled trial. JAMA. 2004;291:79-87.

Rello J, Afonso E, Lisboa T, Ricart M, Balsera B, Rovira A, Valles J, Diaz E, Investigators F. A care bundle approach for prevention of ventilatorassociated pneumonia. Clin Microbiol Infect. 2013;19:363-9.

Restrepo RD, Braverman J. Current challenges in the recognition, prevention and treatment of perioperative pulmonary atelectasis. Expert Rev Respir Med. 2015;9:97-107.

Rogerson D, Williams JP, Yates S, Rogers E. Epidemiology, practice of ventilation and outcome for patients at increased risk of postoperative pulmonary complications. Eur J Anaesthesiol. 2017;34:492-507.

Shander A, Fleisher LA, Barie PS, Bigatello LM, Sladen RN, Watson CB. Clinical and economic burden of postoperative pulmonary complications: patient safety summit on definition, risk-reducing interventions, and preventive strategies. Crit Care Med. 2011;39:2163-72.

Spreadborough P, Lort S, Pasquali S, Popplewell M, Owen A, Kreis I, Tucker O, Vohra RS. A systematic review and meta-analysis of perioperative oral decontamination in patients undergoing major elective surgery. Perioper Med. 2016;5:6.

Villar J, Kacmarek RM, Pérez-Méndez L, Aguirre-Jaime A. A high positive endexpiratory pressure, low tidal volume ventilatory strategy improves outcome in persistent acute respiratory distress syndrome: a randomized, controlled trial. Crit Care Med. 2006:34:1311-8.

Wang L, Li X, Yang Z, Tang X, Yuan Q, Deng L, Sun X. Semi-recumbent position versus supine position for the prevention of ventilator-associated pneumonia in adults requiring mechanical ventilation. Cochrane Libr. 2016;

Yang W, Liu Y, Zhang Y, Zhao QH, He SF. Effect of intra-operative high inspired oxygen fraction on surgical site infection: a meta-analysis of randomized controlled trials. J Hosp Infect. 2016;93:329-38.

\section{Submit your next manuscript to BioMed Central and we will help you at every step:}

- We accept pre-submission inquiries

- Our selector tool helps you to find the most relevant journal

- We provide round the clock customer support

- Convenient online submission

- Thorough peer review

- Inclusion in PubMed and all major indexing services

- Maximum visibility for your research

Submit your manuscript at www.biomedcentral.com/submit

) Biomed Central 